\title{
EL TIEMPO EN LA ANTIGÜEDAD Y EN LA ÉPOCA MODERNA
}

\author{
Antonio Peña Cabrera \\ Universidad Nacional Mayor de San Marcos \\ LIMA, PERÚ
}

0. En el presente trabajo se estudia la evolución de la idea de tiempo desde la Antigüedad clásica griega hasta Newton. Se ha tomado para seguir el hilo de la evolución, y en verdad como punto de partida, el concepto de tiempo en Aristóteles. No es la única idea de tiempo que hubo en la Antigüedad y en el Medioevo, pero fue la predominante; de modo que atendiendo a las discusiones que esa idea promovió en las distintas situaciones históricas y culturales de Occidente, se llega uno a explicar la Revolución copernicana, en un primer momento, y el concepto de tiempo absoluto de la física de Newton, en un segundo momento. Se han dejado de lado en este trabajo las ideas sobre el tiempo contenidas en el Kaläm y expresados por el mutakallimün, cspecie de teólogo musulmán, que influyeron en algunos pensadores cristianos de Occidente, en Roberto Grosseteste por ejemplo, pero que no tuvieron mayor repercusión ni hicieron variar el curso de la discusión dentro de la Escolástica. La idea de tiempo del mutakallimün es atomista. La teología islámica adoptó desde el comienzo el modelo democriteo. Según el mutakallimūn el tiempo es discontinuo y consiste, en consecuencia, en una sucesión de momentos. En Dios es esa sucesión infinita. Para Aristóteles el tiempo es continuo. Tampoco se ha considerado la idea de tiempo existencial, ya que —salvo en un caso aislado: el de Pedro Juan Olivi (1248-1298)nadie aparentemente se preocupó por el tiempo como experiencia existencial. Y el caso de Olivi es típico porque él mismo tampoco se aventuró a defender la idea de tiempo existencial como propia, lo cual es históricamente explicable: sus ideas sobre el alma humana habían sido condenadas por la Iglesia. La tesis del tiempo existencial lleva a concebir el tiempo como algo subjetivo y objetivamente como algo irreal. Es un dogma cristiano sin embargo que el tiempo como toda criatura es un ens reale.

Son frecuentes los estudios que buscan explicar la Revolución coper- 
nicana siguiendo la evolución y cambio de las ideas de espacio, vacío, movimiento. Son raros en cambio los que tratan de explicar esa Revolución por lo sucedido con la idea de tiempo desde la Antigüedad. Aun más, los trabajos que conciernen al tema del tiempo lo abordan en forma parcial y fragmentaria. La justificación del presente estudio, si acaso la tiene, sería la de llamar la atención sobre la importancia del tema no sólo para conocer mejor el nacimiento de la ciencia moderna, sino incluso para ver cómo se ha ido constituyendo el pensamiento occidental desde sus orígenes.

1. Todos tenemos hoy una idea lineal del tiempo: un punto que recorre uniformemente una línea recta infinita. El movimiento uniforme, regular y continuo es la imagen ideal del tiempo a la que se aproxima el ritmo regular de cualquier reloj (cósmico, mecánico, de cuarzo o atómico).

Pero éste no es el tiempo mítico. En el mito -el griego, que es el punto de partida de la especulación sobre el tiempo en Occidente- los dioses y semidioses tienen su tiempo propio que es perfectamente reversible: lo pasado puede actualizarse y lo futuro adelantarse. Hesiodo cuenta en su Teogonia que el mundo ha salido de la noche y el caos. El mundo no se ha originado en el tiempo sino que el tiempo es algo que ocurre en el mundo como si los dioses lo crearan y tuviesen dominio sobre él. Hesiodo habla de un comienzo y fin del mundo.

2. Aristóteles critica esta cosmogonía: no puede haber comienzo o fin del mundo, pues ello implica contradicción. El comienzo señala siempre el fin de algo distinto y viceversa. Cualquier instante es como el punto en una línea infinita que siempre tiene puntos antes y puntos después. El tiempo, pues, no tiene término como tampoco comienzo; tanto lo que está antes del comienzo como lo que está después del fin están en el tiempo. Para Aristóteles, sin embargo, el tiempo no es una substancia sino una determinación del movimiento, de suerte que si el tiempo es infinito (en el sentido anotado), lo es porque el movimiento es infinito. Aristóteles enfrenta aquí una dificultad. Todo móvil en movimiento tiene la capacidad de moverse, puede en consecuencia no estar en movimiento. Lo que actualmente se mueve se mueve por acción de otro movimiento. Pero ésta no es una cadena infinita. Es necesario entonces suponer que hay una causa del movimiento que no es móvil: el motor inmóvil. Dios es el motor inmóvil, pero es también el fin del movimien-

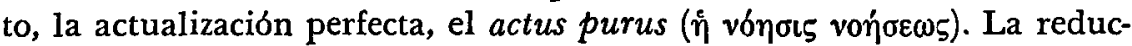
ción de la expresión de Dios a estas funciones es en lo que consiste el proceso de desmitificación de Dios llevado a cabo por Aristóteles y que sirve para la racionalización de la realidad.

El motor inmóvil es la causa de un movimiento continuo. Para Aris- 
tóteles el único movimiento continuo es el local y entre los movimientos locales, el circular, pues es el que no tiene principio ni fin. En consecuencia, este movimiento, que Aristóteles identifica con la primera esfera, la de las estrellas fijas, es eterno. El movimiento de la esfera de las estrellas fijas es a su vez la causa de los otros movimientos. ${ }^{1}$

Es conocida la definición del tiempo formulada por Aristóteles: la me-

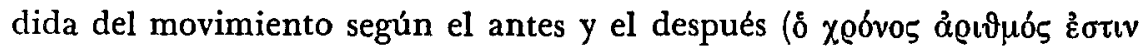

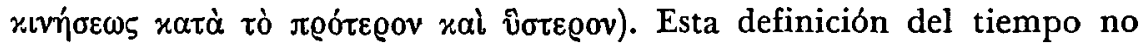
puede ser útil a menos que haya un movimiento regular, uniforme y continuo por el que puedan medirse otros movimientos. ${ }^{1 \mathrm{a}}$ En efecto, si ha de medirse un movimiento según el antes y el después ha de usarse otro movimiento cuya regularidad, uniformidad y continuidad sean garantía absoluta de determinación de aquel movimiento. La definición del tiempo de Aristóteles exige, en una suerte de argumento cuasi ontológico, la existencia del movimiento regular, uniforme y continuo que no es otro - según lo dijimos- que el primum mobile, esto es, el cielo de las estrellas fijas.

2.3. Si se compara la definición del tiempo de Aristóteles con la de Platón se hará más clara la exigencia ontológica de la existencia de un movimiento regular, eterno, continuo y uniforme. Es sabido que para Platón el tiempo es algo que compete a lo corruptible. Ahora bien, en lo corruptible - que es todo lo sensible y corpóreo para Platón- todo es inexacto, impreciso y, en consecuencia, irregular. El mundo de la perfección es el de las ideas. El tiempo para Platón es por eso la "imagen móvil de la eternidad". Aristóteles al contrario enseña que el movimiento de los astros es perfecto, absolutamente regular y continuo en virtud de dos cosas: por la acción permanente del motor inmóvil y por estar constituidos de una materia cuasi divina: el éter. ${ }^{2}$ Los cuerpos celestes se mueven sin principio ni fin y son incorruptibles.

2.4. Pero si el cielo está en movimiento circular uniforme y continuo, la tierra permanece en reposo en el centro del universo. Esta cosmovisión geocéntrica corresponde a la peculiar actitud del hombre griego documentada en el lenguaje. Los fenómenos no se descubren ni se les fuerza a aparecer: ellos se manifiestan. "Fenómeno" tiene en griego un sentido activo. paívoua significa "yo me aparezco". Las cosas se aparecen por sí mismas y sólo hay que contemplarlas. El conocimiento de

I Metafísica, Lib. XII, cap. VI y VII.

${ }^{2}$ Física, Lib. IV, cap. XIV, 223b, 20-25.

2 Platón y Aristóteles han hecho derivar la palabra "éter" de ốî́ áxi. El éter es así un cuerpo que se mueve sin principio ni fin eternamente. (Cratilo 410b75; De Caelo I, 3, 270b23). 
ellas se hace mirándolas. Teoría es el acto de contemplación. De ese modo, el alma debe abrirse a las cosas y dejarse penetrar por las manifestaciones de ellas. El sujeto en la contemplación permanece en reposo en tanto que son los fenómenos los que se mueven. Esta relación reposo movimiento es simétrica con la de la tierra inmóvil en el centro del universo y las esferas celestes girando alrededor.

Aristóteles trata especificamente sobre el tiempo en la Fisica, Lib. IV, caps. 10-14. Alli se dice lo que ya hemos registrado: que el tiempo es la medida del movimiento según el antes y el después. Se afirma también que no hay tiempo sin movimiento ni movimiento sin tiempo. El sujeto del tiempo es el movimiento, aunque en rigor es el móvil en movimiento. Es al final del cap. 14 donde Aristóteles dice dos cosas importantes: 1. que el tiempo no sólo es medida del movimiento sino que a su vez es medido por el movimiento y 2. que esa medida perfecta del tiempo es el movimiento de la primera esfera. Esto es lo que importa retener por lo que se dirá a continuación.

3. La concepción aristotélica del tiempo es recibida en el medio latino cristiano de comienzos del siglo xin junto con todo el corpus aristotelicum. Hasta entonces no se conocían de Aristóteles más que las Categorias y el Peri-hermeneias y quizá los Primeros analiticos. Junto con las obras de Aristóteles fueron introducidos en Europa las Glosas que Avicena escribió a ellas y los Comentarios de Averroes. De modo que los cristianos leyeron a Aristóteles auxiliados por la lectura de Avicena y Averroes, quienes hacen precisiones pero también alteraciones al pensamiento del Estagirita, sobre todo en lo referente al concepto del tiempo. Es Avicena el que concibe por primera vez que el movimiento de la primera esfera no sólo es la medida universal del tiempo sino también su sujeto. Los otros movimientos no tienen tiempo sino por ser efectos de la primera esfera. ${ }^{3}$ Si la primera esfera cesara de rotar no sólo cesarían los otros movimientos sino que acabaría también el tiempo, puesto que no hay tiempo sin movimiento.4 Averroes precisa lo dicho por Avi-

3 "... c'est bien chez Avicenne qu'on trouve d'abord et dans les termes les plus formeles l'idee que le temps n'a d'existerice que dependamment du mouvement propre a un seul mobile determine, qui n'est autre que la premiere sphère du ciel" A. Mansion: "Le temps chez les péripatéticiens médiévaux", en Rev. Néoscolastique de Philosophie, Louvain, t. 36, fév., 1934, p. 292: "... es en Avicena donde se encuentra por primera vez y en los términos más claros la idea de que el tiempo sólo tiene existencia que depende del movimiento propio de un solo móvil determinado, que no es otro que la primera esfera del cielo."

4 Si autem quis dixerit quod si non esse ille motus (circularis corporis sperici) non esset tempus, it quod in omnibus motibus aliis preter illum non esset prius et posterius. El sicut diximus in opinionibus et corpus non habet necesse ut sit corpus mobile ad motum alterius corporis. Erit ergo possibile ut moveatur et non 
cena. No es necesario percibir el movimiento de la primera esfera para percibir el tiempo. Lo percibimos en nosotros mismos, en nuestro esse transmutabile que es efecto de los cambios del cielo. ${ }^{5}$ El tiempo es percibido por nosotros primero y esencialmente en el movimiento interno que nos afecta directamente y que muestra nuestra capacidad esencial de cambio. Lo que no quiere decir que el tiempo no tenga como sujeto único el primum mobile. Según el pensamiento árabe aquí sintetizado hay una relación causal continua pero escalonada entre la primera esfera, las demás esferas estelares y el mundo sublunar, en un proceso hipostático. La influencia neoplatónica en los pensadores árabes, aun en Averroes, es, pues, neta. La concepción árabe permite sin embargo una cierta homogeneización entre el cielo y la tierra que facilitará la tarea del pensador cristiano, que distinguirá claramente entre el Creador y la criatura.

3.1. Tanto Alberto Magno como Tomás de Aquino aceptan sin reservas la concepción del tiempo de los árabes, quienes introducen modificaciones notables en el pensamiento aristotélico. Sed hic per omnia Arabes sequi disposui —dice Alberto- quia puto quod intellectus eorum de tempore est verus (pero aquí sigo en todo a los árabes, porque pienso que la intelección que tienen ellos del tiempo es verdadera). ${ }^{6}$

3.1.1. Con Alberto tres posiciones son muy claras: 1. El tiempo es la

sit tempus. Responsio ad hoc hec est: quia postea declarabimus quod si no esset motus circularis corporis sperici: motus recti non haberent loca: nec essent motus recti naturales, nec essent motus per vim. Ergo posse esse motum unius corporis tantum absque aliis corporibus est impossibile ... Avicena, Sufficientia, II, 13. En Avicena, Opera, 1508: "Pero si quien dijera que si no hay tal movimiento (esto es, el de la primera esfera) no habría entonces tiempo, es decir, que en todos los demás movimientos amén de aquél no habría ni antes ni después. $Y$ así diríamos, con las opiniones de aquéllos, que el cuerpo para que sea cuerpo móvil no tiene necesidad de estar en relación con el movimiento de otro cuerpo. Serfa entonces posible que se moviera y que no hubiera tiempo. Respondo a esto de la siguiente manera (que luego explicaré): que si no existiese el movimiento circular del cuerpo esférico, los movimientos rectos no tendrían lugares, ni existirían los movimientos rectos naturales ni los movimientos violentos. En consecuencia, es imposible que haya movimiento de un solo cuerpo sin los otros cuerpos..." Avicena, Sufficientia, II, en Opera, 1508, f. 35.

5 Et iam declaravimus prius quod nos percipimus tempus, quando percipimus motum, per quem sentimus nos esse in permutatione continua, et est motus circularis. Averroes, cit. por Mansion, op. cit., 286. Et manifestum est quod nos non sentimus nos esse in esse transmutabile, nisi ex tramutatione caeli. Et si esset possibile ipsum quie scere, esset possibile nos esse in esse non transmutabile, sed hoc est imposibile. Averroes, cit. por Mansion, op. cit., p. 282: "Y ya hemos dicho antes que percibimos el tiempo cuando percibimos el movimiento, por el cual nos sentimos estar en continuo cambio; y el movimiento circular". Averroes, citado por Mansion, op. cit., p. 286. "Y es manifiesto que no nos sentimos como seres mutables sino por la mutabilidad del cielo. $\mathrm{Y}$ si fuese posible que el cielo cesara de moverse, sería posible que nosotros fuésemos un ser no mutable, pero esto es imposible." Averroes, citado por Mansion, op. cit., p. 282.

6 Phys. IV, tract. III, cap. 6, p. 218b, ed. Borgnet, vol. III. 
medida inmediata del primum mobile y está en él como la forma en su sujeto (sicut forma in subjecto). En los otros movimientos está como número numerante o número extrínseco (sicut numerus extrinsecus applicatus rebus numeratis). ${ }^{7}$ El tiempo está pues en el primum mobile como en su medida apropiada, como en su sujeto que entra en la definición del tiempo, ${ }^{8}$ en los otros movimientos está como un número abstracto, como algo extrínseco. 2. El tiempo está en todos los movimientos pero de diverso modo a como está en el primum mobile, así como la luz se difracta en los diferentes objetos sin dejar de ser la misma luz procedente de una sola fuente (tempus esse mensuram aliorum temporum, non intelligimus plura esse tempora, sed unum diversi modo referi multa). ${ }^{\circ}$ 3. Alberto busca explicar la percepción del tiempo en cualquier movimiento y no sólo a través del alma como lo pretendía Averroes. La causa de todos los movimientos que es la primera circularidad se descubre en los efectos, pero no por inducción (collatio) sino directamente (advertatur et percipiatur distincte). Si el tiempo está en el primer móvil como en su sujeto lo está en los movimientos derivados por la relación de causalidad.

3.1.2. Santo Tomás expone con más claridad las relaciones entre el movimiento primero y los demás movimientos, y entre el tiempo, cuya predicación conviene sólo al primer móvil, y el que por forma derivada corresponde también a todas las otras cosas sujetas a cambio. "El tiempo es por sí medida del primer movimiento (mensura primi motus) y es del ser de las cosas temporales (esse rerum temporalium) en tanto que éste se halla sujeto a las variaciones del movimiento estelar... De donde pues, desde que todas las cosas están sujetas al movimiento del cielo como a su causa, son medidas también por el tiempo, cuya medida primera es aquel movimiento estelar. Quienquiera que percibe cualquier variación, que es consecuencia de la variación del primer cielo, percibe el tiempo mismo aunque no vea el movimiento estelar". ${ }^{10} \mathrm{El}$ tiempo tiene como sujeto el primum mobile - tal como lo decía Avicena- y percibimos ese tiempo directamente en todas las cosas, no sólo a través de nuestro esse variabile, como ya lo había distinguido Alberto corrigiendo a Averroes. El Doctor angélico establece con claridad la relación causal entre el primer móvil y los otros movimientos, de tal manera que en cualesquier movimientos se percibe el movimiento del primum mobile y por ese medio se miden esos movimientos. Ahora bien, medir el movimiento

7 Op. cit., pp. 34lb-342a.

8 Loc. cit.

O Op. cit., p. $341 \mathrm{~b}$.

oa Op. cit., cap. 4, p. 313.

10 I Sent. w. 19, q.a, a.I ad 4 tam. 
por otro movimiento es en lo que consiste el tiempo.11 Lo que había sido esbozado por Alberto pero no bien aclarado, esto es, la paralelidad entre la relación causal y la relación temporal, queda expresado con rigor y coherencia por Santo Tomás.

Está bien claro que para Santo Tomás el movimiento del primer cielo no sólo es la medida de los otros movimientos sino también el sujeto único del tiempo, con lo que se explica la unidad del tiempo que es lo que a fin de cuentas se trata de probar. Tempus est unum ab unitate motus primi mobilis, tempus autem comparatur ad istum motum, non tantum ut mensura, sicut ad alios motus, sed sicut accidens ad subjectum, quod ponitur in diffinitione eius. ${ }^{12}$ Como se ve por este pasaje, la posición de Santo Tomás es casi puntualmente la de Averroes. Agustín Mansion ha señalado que esta actitud es vigente en Santo Tomás sólo hasta 1268, pues en las obras posteriores aunque trata del tiempo, incluso en forma exhaustiva como en el Comentario a la Fisica de Aristóteles, no se halla la expresión de que el primer móvil es el único sujeto del tiempo. ${ }^{13} \mathrm{Si}$ bien esto es cierto, la tesis en lo fundamental continúa igual. Precisamente en el Comentario a la Fisica Santo Tomás reproduce el argumento de Averroes por el cual se explica que todo cambio depende del cambio en el primum mobile, de modo que al percibir el cam. bio de cualquier cosa, se percibe al "primum motum quem sequitur tempus". Y agrega: "licet tempus non consequitur nisi motum primum a quo omnes alii causantur et mensurantur: et sic remanet tantum unum tempus". ${ }^{14}$ Este primer movimiento al que sigue el tiempo como su accidente es a lo que en obras anteriores el Aquinatense llama "sujeto".15

3.1.3. Como queda dicho, los peripatéticos latinos, Alberto Magno y Tomás de Aquino en especial, siguen a Averroes casi puntualmente en lo que se refiere al tiempo, lo atacan sin embargo, en otros puntos, como

11 Phys. Lib. IV, Lec. xxiii, 11: Motus mensurantur a tempore, inquantum mensurantur quodam motu.

12 II Sent. d.2, q.1, a.l. "El tiempo es uno por la unidad del movimiento del primer móvil, pero el tiempo se compara con este movimiento no sólo como medida, como lo es con los otros movimientos, sino también como accidente con respecto al sujeto, que es expresado en la definición de aquél."

13 Mansion, op. cit., pp. 304-307.

14 Phys. Lib. IV, Lec. xvii, 4. También: Lec. xxiii, 635: necesse est dicere quod tempus sit numerus primae circulationis, secundum quam mensuratur tempus et ad quem mensuratur omnes alii motus temporis mensuratione: «Aunque el tiempo no sigue más que al primer móvil, por el cual son causados y medidos todos los demás: de ese modo sólo hay un tiempo.» Lec. xxiii, 635: «s necesario decir que el tiempo es el número del primer movimiento circular, segín el cual es medido el tiempo y con referencia al cual son medidos con la medida del tiempo todos los demás movimientos.»

15 Especialmente en el Comentario a las Sentencias escrito entre 1254 y 1256, la primera parte de la Summa Theologica (1265-1268) y De spiritualibus creaturis de 1266-1268. 
en el que concierne al alma humana. Ahora bien, Averroes se aparta de Aristóteles en puntos fundamentales en lo que concierne al tiempo. El

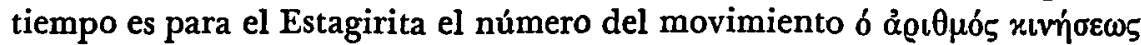
pero el número entendido como lo contable y no como lo que enumera, como lo enumerado y no como lo abstracto o extrínseco. De esa manera el tiempo es lo medible del movimiento, de cualquier movimiento y no sólo del primum mobile, como sin embargo lo afirman Avicena, Averroes, Alberto Magno y Tomás de Aquino. ${ }^{10}$

El tiempo tiene como sujeto, según el Estagirita, el movimiento, y más exactamente, el móvil en cuanto se halla en movimiento. ${ }^{17}$ Para los árabes y los peripatéticos latinos, el primum mobile es el único sujeto del tiempo. Aristóteles no busca la fundamentación de la unidad del tiempo en una causa eficiente única sino en la naturaleza del tiempo. Si dos movimientos son simultáneos entonces sus tiempos son uno y el mismo. ${ }^{18}$ Cuando Aristóteles recurre al cielo de las estrellas fijas como realización del tiempo, lo toma como la encarnación de la medida absoluta del tiempo, pero no como el sujeto único del tiempo.10

Estos puntos resumen las divergencias entre Aristóteles por un lado, y Averroes y los que lo siguen, por el otro. Para éstos el peso de la explicación de la unidad del tiempo se carga sobre la causa única de todo lo corpóreo: el primum mobile, con lo que consiguen una explicación sistemática, cerrada y consecuente, que no se aprecia en Aristóteles, pero sumamente vulnerable. Contra el racionalismo del sistema se va a reaccionar pronto. Es esa reacción la que nos ocupará inmediatamente.

3.2.1. El primer crítico de la posición causalista del tiempo es Roger Bacon (1214-1292). La unidad del tiempo no tiene fundamento en el movimiento estelar ni el primer cielo es el sujeto absoluto del tiempo. Si el cielo se detuviese y quedaran los otros movimientos habría tiempo, pues según el Estagirita no hay movimiento sin tiempo. Éste es un argumento b́blico usado antes por San Agustín precisamente con igual propósito: para probar que el cielo no es sujeto del tiempo. ${ }^{20}$ Pero la tesis de Avicena y Averroes es que si el cielo cesa de moverse también cesan eo ipso todos los demás movimientos, por haber una relación de

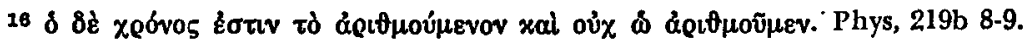

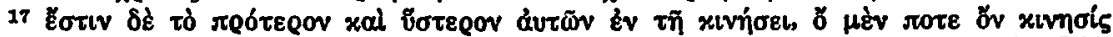

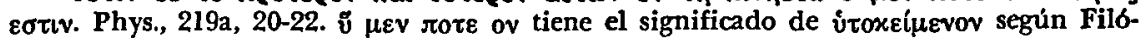
ponos, esto es, de substancia, de la que el tiempo es accidente, lo que corresponde a la relación sujeto-predicado. Según el contexto del cap. xI del Lib. IV, de la Física, íroxeífevov es lo que corresponde al instante, esto es, el móvil en cuanto se halla en movimiento. El movimiento es en verdad una abstracción: el recorrido del móvil.

18 Fisica, Lib. IV, cap. Xrv, 223b, I-4.

19 Op. cit., 223b, 22.

20 San Agustín, Confesiones, Lib. XI, caps. 23, 30. 
causa efectiva entre uno y los otros. A esta consideración del Doctor Mirabilis contrapone la de que el movimiento circular no puede ser causa de los movimientos rectilíneos como son los de los elementos constituyentes de los cuerpos sublunares. Además, dice Roger, el cielo es causa de la generación, la corrupción, el crecimiento y decrecimiento, esto es, "causa motus secundum formam, sed non motus recti localis". ${ }^{21} \mathrm{Y}$ más alejados de la influencia estelar están los movimientos voluntarios, que son libres y que, en consecuencia, no podrían estar determinados. ${ }^{21 a}$ De modo que el cese del movimiento estelar no puede causar el cese de todos los demás movimientos $\mathrm{y}$, por ende, del tiempo. Roger exhibe también otro argumento aristotélico contra las tesis averroistas. Si existieran varios cielos de mundos independientes, habria entonces pluralidad de tiempos. Este argumento que es ad absurdum en Aristóteles para combatir a los que suponen que el tiempo es el cielo, es perfectamente válido dentro del dogma cristiano de la omnipotencia divina. Roger Bacon trae a colación además argumentos de indole ideológica que quizás no sean para nosotros relevantes, pero que en ciertas ocasiones en el Medioevo eran los decisivos. El movimiento de los cuerpos glorificados -dice Roger- no puede estar afectado ni condicionado por el movimiento estelar, que no es glorificado. Hacer del primum mobile sujeto precisum del tiempo tiene por objeto fundamentar la unidad del tiempo, pues si éste fuera accidente de cualquier movimiento entonces habría tantos tiempos como movimientos, asi como hay tantos accidentes como substancias, cuando menos. Hemos visto que para el Estagirita los movimientos simultáneos son de uno y el mismo tiempo, pero no aporta prueba. $Y$ esto es lo que va a hacer Roger. Todo lo que es dimensionado excluye a lo que es dimensionado de la misma manera, pero los que no son dimensionados no se excluyen. Una línea que tiene sólo dimensión de longitud excluye a otra línea sólo en esa dimensión, pero no la excluye en latitud y profundidad, porque no son dimensionadas en estas dimensiones, en consecuencia, en lo que respecta al ancho y a la profundidad una línea es indivisa, indistante, indiferente y unida a otra

21 Roger Bacon atribuye este pensamiento a Aristóteles: Aristóteles enim dicit in fine De Generatione, quod motus celi fit ut adducatur generans per varias partes habitabilis, scilicet, sol et alie stelle. Set motus rectus elementorum non est annexus generacioni et corrupcioni, et ideo non dependet a motu celi; quare, stante celo, lapis descendet deorsum. Communium naturalium, O.H.I. Oxford, I91I (vol. III), p. 160: -Aristóteles dice al final del libro Sobre la generación y la corrupción que el movimiento del cielo hace que el que genera, esto es, el sol y las estrellas, gire por todas las partes habitables. Pero el movimiento recto de los elementos no está ligado a la corrupción y a la generación y, en consecuencia, no depende del movimiento del cielo; porque al pararse el cielo, la piedra (siempre) descenderfa.

21a Roger Bacon, Communium naturalium, O.H.I. Oxford, 1911, pp. 158-168. 
línea. ${ }^{21 b}$ Un punto que no es dimensionado no excluye a otro punto, esto es, son uno y el mismo punto. El movimiento no tiene más que la dimensión de longitud en el espacio, esto es, va de lo pasado a lo futuro en forma lineal, en consecuencia, con respecto al presente, que es un punto, no tiene dimensión y no excluye el presente de otro movimiento: simul possunt esse plures motus in presenti, licet preteritus et futurus simul esse non possunt.

$\mathrm{La}$ tesis de Bacon es intrincada y no suficientemente convincente. Novedosa lo es, sin duda. Él sostiene, siguiendo a Aristóteles, que cualquier movimiento es sujeto de tiempo: nullus motus datus est precisum subjectum temporis; ita quod non alius set omnis motus indifferenter. Pero si es accidente de cada movimiento el tiempo debe multiplicarse con los movimientos, como sucede con los accidentes. Sin embargo el accidente temporal como el espacial son diferentes. Si dos cosas no se distinguen por su dimensión y por su distancia entonces son una y la misma. El movimiento es una línea que va del pasado al futuro, se distingue de otro movimiento en lo que respecta al pasado y al futuro, pero en el presente son indistinguibles en su temporalidad. De esa manera, afirma Roger, aunque el tiempo se debe a muchos movimientos, no se debe a ellos como sujeto sino como cosas, pues el sujeto del tiempo de muchos movimientos simultáneos no son las cosas que se mueven simultáneamente sino el decurso que va del pasado hacia el futuro.

La argumentación baconiana con toda su originalidad no tuvo sin embargo repercusión en la Escolástica, salvo en algunos escotistas, y en los que con igual propósito usaron parte del argumento pero sin nombrar a su autor. Acaso la debilidad de la argumentación resida en la mezcla que hace el Doctor Mirabilis entre lo abstracto y lo concreto, entre lo ideal y lo real. El tiempo para los escolásticos es un ens reale, pero definirlo, como se definen líneas, planos y puntos, es hacer del tiempo justo lo que no se quiere: un número abstracto. Lo notable en Bacon es su posición claramente antiaverroísta que concuerda, por lo demás, con la ortodoxia cristiana, que va a expresarse en la condenación de 219 tesis averrolstas según el Decreto del obispo de Paris, Stephan Tempier, del 7 de marzo de 1277.

3.2.2. El Decreto condenatorio del obispo Tempier expresa la atmósfera reinante en el medio ortodoxo cristiano de París de fines del siglo xiIr, de rechazo al racionalismo aristotélico averroísta. Hay tres tesis

21b Loc. cit.: Nam hec duo, scl., ubi, et duracio presens, debentur rebus per naturam unionis et indivisionis, et indistancie, et per privacionis dimensionis, et ideo una res subjecta eis non excludit aliam, sicut patet de ubi plurium linearum secundum profundum et latum, et de ubi plurium superficierum secundum profundum, quia ubi debetur hic pluribus rebus, in quantum sunt indivisibles et indistantes per privacionem dimensionis, que facit distanciam. 
en ese Decreto que tienen que ver con la explicación de la unidad del tiempo, que son:

69: Dios no puede causar el efecto de una causa segunda sin la causa segunda misma.

79: Si el cielo se detuviera, el fuego no haría arder la estopa, porque entonces la naturaleza no existiría.

77: El cielo nunca se detiene, porque la generación de las cosas inferiores no debe cesar. Otra razón: porque el cielo obtiene su ser y su capacidad de operación de su actividad motora; y el cielo conserva a ésta por su movimiento. De donde, si cesare el cielo de moverse, cesaría de ser. ${ }^{22}$

El rechazo de estas tres tesis sostenidas no sólo por los averroistas sino también -como hemos visto- por Alberto Magno y Tomás de Aquino en forma tácita, significa que Dios puede actuar directamente allí donde el sistema aristotélico averroísta señala que sólo puede hacerlo a través de causas segundas, esto es, a través del cielo. Que aun deteniéndose el cielo las cosas del mundo sublunar podrían seguir moviéndose; esto lo cree el cristiano porque una historia semejante se relata en la biblia. Josué con ayuda de Dios detuvo el sol y la luna por un día hasta que el pueblo de Israel tomara venganza contra sus enemigos. (Josué 10, 12-14). Las cosas creadas no están encadenadas por medio de una causalidad estricta. No hay pues razón con el supuesto de un Dios omnipotente, para afirmar que el cielo es el sujeto precisum del tiempo y la causa necesaria del movimiento y de la generación de todas las cosas inferiores. En el espíritu de la Condenación se nota claramente la relevancia de la idea de un Dios omnipotente sobre el concepto de un Dios racional. En lugar de un intellectus infinitus se afirma la idea de una potentia Dei absoluta. Dios es entonces capaz de hacer hasta lo inimaginable por el hombre y, en consecuencia, su acción no podría estar constreñida por ningún sistema racional por más coherente que fuera. Antecedentes de esta posición hallamos en San Agustín y, como acabamos de ver, en Roger Bacon.

3.3.1. La preocupación del pensador cristiano será - teniendo en cuenta los límites trazados por el Decreto de 1277_ formular una relación

22 Roland Hissette, Enquête sur les 219 articles condamnés d Paris le 7 Mars 1277, Louvain, 1977: 69. Quod Deus non potest in effectum causae secundariae sine ipsa causa secundaria. 79. Quod si caelum staret, ignis in stupam non ageret, quia natura deesest. 77. Quod caelum nunquam quiescit, quia generatio inferiorum, quae est finis motus caeli, cessare non debet; alia ratio quia caelum suum esse suam virtutem habet a motorex suo; et hace conservat caelum per suum motum. Unde, si cessaret a motu, cessaret $a b$ esse. 
causal menos estricta, no efectiva, entre el primus motus y las demás cosas, a fin de no abandonar totalmente las bases de la argumentación en favor de la unidad del tiempo, que es una manera a su vez de probar su realidad. El tiempo tiene que ser un ens reale, pues según la ortodoxia cristiana Dios ha creado el tiempo; éste no puede ser ni una ficción ni una creación del alma. Una de las tesis condenadas, que se refiere expresamente a la irrealidad del tiempo, es la siguiente: Quod aevum et tempus nihil sunt in re, sed solum apprehensione. ${ }^{23} \mathrm{La}$ unidad del tiempo es garantía de su trascendencia con respecto al alma. Por el contrario, si el tiempo tuviese como sujeto cualquier movimiento, habría tantos tiempos como movimientos y la reducción del tiempo al movimiento sería inevitable; el tiempo no seria sino una forma de aprehensión del movimiento por el alma humana (solum apprehensione).

Se va a distinguir en un primer momento entre un tiempo intrínseco, que es propio de cada movimiento, y un tiempo extrínseco que es el tiempo propiamente y que está con propiedad sólo en el primum mobile. La percepción de este tiempo extrínseco no va a darse sin embargo a través de la percepción del esse trasmutabile como efecto de la variación del cielo, sino como efecto del acto de la medición. La medida se distingue de lo medido numéricamente, pero la operación de medición supone que entre la medida y lo medido hay una comunidad de género.

3.3.2. Según Godofredo de Fontaines ${ }^{24}$ hay una medida genérica y una medida propia. El "codo" es una medida propia cuando define el sujeto de que es accidente, y es genérica cuando mide otras cosas, por ejemplo paños o telas. En este sentido el tiempo es medida propia del movimiento del cielo. Es medida genérica de todos los otros movimientos.

3.3.3. Ricardo de Mediavilla ${ }^{25}$ se preocupa por determinar el tipo de relación causal que habría entre el primum mobile y los motus inferiorum corporalium. La relación causal se definiría por la perfección de la causa con respecto al efecto. El acto de medir es una suerte de causa de conocimiento de algo imperfecto e impreciso por algo más perfecto y más preciso. El movimiento estelar es la medida propia del tiempo en virtud de su regularidad, uniformidad y continuidad. Pero este tipo de causalidad de carácter pragmático no tiene que ver en absoluto con la causalidad efectiva.

3.3.4. Guillermo de Ware $^{26}$ rechaza enfáticamente la relación causal eficiente entre el motus primus y los otros movimientos en virtud de

23 Op. cit., pp. 152-154. "Que la duración y el tiempo no están en lo real sino sólo en la aprehensión."

24 Del clero secular, enseñó en París en la época en que se emitió el Decreto. Fue colega de Enrique de Gante. Murib entre 1306-1309.

25 Franciscano inglés que enseñó en Paŕs alrededor de 1283. Murió en 1307.

26 Maestro de Duns Scoto, enseñó en Paris a fines del siglo xur. 
dos razones: una porque podría detenerse el movimiento del sol o del cielo y no por ello tendrían que cesar los otros movimientos. Y segunda, porque el movimiento de los planetas va en sentido contrario al movimiento de la supuesta causa: el cielo de las estrellas fijas. La primera tiene su fundamento - como ya hemos visto - en el testimonio bíblico y en la tradición cristiana. La segunda es el resultado de la observación: aliqui dicunt quod motus planetorum a nullo dependet a motu primi corporis, quia motu contrario moventur. ${ }^{27}$ Lo que no quiere decir que no se midan los movimientos de los planetas por el del primum mobile, cuya perfección es reconocida por Guillermo de Ware. Pero esta perfección es a lo sumo una suerte de causa formal y nada más: aliquo modo causa formalis secundum perfectionem extrinsecam.

3.3.5. Hervaeus Natalis ${ }^{28}$ fue un pensador muy sutil. Distingue como los anteriores entre un tiempo extrínseco y muchos tiempos intrínsecos, tantos como movimientos; sin embargo a la pregunta "utrum omnium temporalium sit unum tempus" responde afirmativamente. Dos son las razones que expone. la: las cantidades sucesivas pueden ser perfectas, cosa que no ocurre con las cantidades permanentes. Hay en efecto un movimiento uniformissimus que es medida de los otros movimientos. La segunda es que la estructura de los movimientos es unidimensional, esto es, los movimientos simultáneos tienen una sola y única dimensión común: omnes motus simul existentes comparati ad invicem no faciunt plus ve minus secundum quantitatem successivam quam unus tantum. De esa suerte, existe una medida única para todos los movimientos simultáneos que es el tiempo extrínseco. Harvaeus precisa más estas ideas. La razón de medida no es causa de lo medido sino que certifica lo medido y lo hace más patente. El color blanco hace que podamos distinguir todos los otros colores en la medida en que se apartan más o menos de la perfección de la blancura (quantum unusquisque déficit a perfectione albedinis) y no por eso se considera que la blancura sea causa eficiente de los demás colores. Es suficiente entonces la existencia de un movimiento uniformissimus, esto es, perfectamente regular que será el apropiado para medir todos los otros movimientos; tal movimiento es el estelar. Pero aun suponiendo que el movimiento estelar se detuviese y que continuaran los otros movimientos, no por

27 Sent II, d, 2, 9.1, citado por A. Maier, Metaphysische Hintergründe der Spät Scholastikenphilosophie. Roma, 1955, p. 119: «algunos dicen que el movimiento de los planetas no depende en absoluto del movimiento del primer cuerpo, porque se mueven con movimiento en sentido contrarios.

28 De la Orden de los Predicadores. Defensor de Santo Tomás de Aquino. Murió en 1323. 
ello habría pluralidad de tiempos, pues siempre existirá una successio nata mensurare successionem aliorum. ${ }^{29}$

El pensamiento de Roger Bacon lo encontramos parcialmente reproducido aquí pero con una argumentación más simple, menos pretenciosa y, a la vez, más completa. Roger Bacon no probó la existencia de una medida universal del tiempo $y$, al revés, concluyó que cualquier movimiento podia ser medida de otros movimientos. Hervaeus destaca la estructura unidimensional de lo sucesivo y el que en la pluralidad de movimientos siempre se puede encontrar, por comparación, el movimiento uniforme con el que se miden los otros movimientos, sin que eso signifique que cualquier movimiento pueda ser medida de cualquier movimiento.

3.4.1. Guillermo de Ockham reduce sin más el tiempo al movimiento. No es necesario suponer algo que esté inherente en el primer móvil para que por él se certifique que otra cosa dura más o menos, que se mueve con más o menos velocidad o que simplemente reposa. Para explicar esto es suficiente suponer el movimiento. Aquí funciona -como se ve- también la "navaja": non entia multiplicanda sine necessitate. En Hervaeus hemos visto cómo se busca definir el tiempo como una cantidad (quantum) que se hace formaliter, esto es en virtud de su esencia, cantidad sucesiva (quantitate successiva). El tiempo es la cantidad sucesiva. Para Ockham en cambio, es inútil buscar otra cosa en el movimiento que el movimiento mismo (ergo frustra ponitur alia res quam motus). De ese modo, el tiempo es para Ockham simplemente el movimiento por el cual el alma mide otros movimientos. ${ }^{30} \mathrm{El}$ tiempo no es un accidente del movimiento, ni siquiera del primus motus.

De acuerdo a la definición que acaba de darse, el tiempo es en sentido restringido el motus primus porque por su regularidad, uniformidad y continuidad sirve para medir los otros movimientos. Lo que no quiere decir que, como en Aristóteles, esta idea de tiempo exija la existencia del movimiento que satisfaga tales condiciones de regularidad, uniformidad y continuidad. Si la existencia del tiempo estuviera condicionada por la existencia de un primer móvil, que sería el cielo de las estrellas fijas, entonces, dentro de la hipótesis perfectamente legítima, desde la perspectiva de una potentia Dei absoluta, que Dios creara muchos mundos, cada uno con su primum mobile, habría muchos tiempos, tantos como mundos, lo que parece absurdo. Según Ockham, los diversos tiempos equivaldrían empero a uno solo: essent unum per aequivalentiam,

29 Sent. II, d. 2, 9.1, a. 4. Ed. Venedig, 1505. Citado por A. Maier, op. cit., pp. 120121. "... una sucesión hecha para medir la sucesión de otros".

30 Tempus est motus quo anima cognoscit quantus est alias motus Questiones in libros physicorum, 9. 40, citado por A. Maier, op. cit., p. 129. 
porque no sería necesario más que uno de ellos para medir todos los otros. ${ }^{31}$ Ockham plantea todavía otra hipótesis, también desde la perspectiva de la omnipotencia divina, para probar que el primus motus no es la medida absoluta y necesaria del tiempo. Dios - dice el Venerabilis Inceptor- puede crear un cielo más veloz que el existente, sin destruir en éste nada de lo que lo constituye. El movimiento de nuestro cielo no sería más el tiempo, no obstante que no habria perdido nada de sus atributos. La designación del primer cielo como reloj cósmico es sólo el resultado de una decisión humana, es la elección de un instrumento para la determinación de otros procesos. ${ }^{32}$

Conviene aclarar que para Ockham el tiempo no es sólo el movimiento; y también, que el tiempo sin el alma es sólo el movimiento, esto es, se reduce al movimiento: tempus potest esse motus sine anima. Pero de ningún modo puede haber tiempo sin el alma: sed nullo modo tempus potest esse tempus sine anima. ${ }^{33}$ Así pues, el tiempo significa stricto sensu una operación del alma.

Ockham cae al final, pues, en lo que los escolásticos habian tratado de evitar caer y cuyo peligro había sido advertido por una de las tesis condenadas por el Decreto de 1277 que ya hemos registrado: quod aevum et tempus nihil sunt in re, sed solum apprehensione, ${ }^{34}$ tesis que entonces pudieron sostener algunos averroístas no muy ortodoxos. Como ya se ha visto, para Ockham el tiempo sin el alma no es, o, mejor, sólo es movimiento; aunque en realidad el tiempo no seria otra cosa que una manera de aprehender el movimiento. ${ }^{35}$ Pero para darnos cuenta de cómo es que cambia la apreciación de las cosas con la época, recordemos aquí

81 Como en Herveus, Ockham piensa que siempre es posible encontrar por comparación un movimiento regular, uniforme y continuo, lo que no lleva necesariamente a pensar que esas regularidad, continuidad y uniformidad sean absolutas. (Summulae in libros Physicorum, IV, c. 11; Questiones in libros physicorum, q. 41.) Con respecto a la posibilidad de la existencia de muchos mundos, Baudry (Lexique philosophique de Guillaume d'Ockham, Paris, 1950, p. 267) dice, comentando a Ockham, lo siguiente: "A moins de renoncer au dogme de la toute puissance divine, el chrétien doit admettre la possibilité de plusieurs univers." Aquí nuevamente encontramos el eco del Decreto condenatorio de 1277 que rechaza la siguiente tesis: Quod prima causa non posset plures mundos facere. (Roland Hissette, op. cit., p. 64): "A menos que se renuncie al dogma de la omnipotencia divina, el cristiano debe admitir la posibilidad de una pluralidad de universos." \&ue la causa primera no puede producir muchos mundos.»

32 Cf. Baudry, op. cit., p. 2665.

33 De successivis, ed. Böhner, N. Y., 1944, p. 99, Quest. in Lib. Phys., q. 48 et 49, Summulae in Lib. Phys. I, c. 16, Quest. ... in IV Sent., II, q. 12.

34 Cf. nota 23.

35 Se ha visto ya que según Ockham, el tiempo sin el alma es el movimiento y nada más que el movimiento. Pero que el tiempo como tal no puede ser sin el alma: tempus potest esse motus sine anima, sed nullo modo tempus potest esse tempus sine anima. De ese modo la diferencia entre el tiempo y el movimiento es puramente subjetiva: solum apprehensione. 
que más o menos 60 años después del Decreto un supuesto averroísta, Juan de Baconthorp sostenfa que la condenación de esa tesis no podía ser entendida como si se dirigiera contra los que sostienen que el tiempo no es nada en cuanto a su fundamento más que el movimiento, porque nunca nadie entre los filósofos modernos (de modernis philosophantibus) ha negado que el movimiento existe fuera del entendimiento. En consecuencia debe entenderse este artículo (de la Condenación) en el sentido de que es un error considerar que el tiempo nada es en la cosa sino sólo en la aprehensión, según sea número del movimiento. ${ }^{36}$ Los autores del Decreto parece que pensaron de manera distinta; lo que se condenó fue el reduccionismo: que el tiempo fuera del alma no sea más que el movimiento y en el alma una abstracción o un modo de operar con el movimiento. ${ }^{37}$ Pero al parecer en la segunda mitad del siglo xIv el reduccionismo era una cosa generalizada y el pensamiento de Ockham y los nominalistas había influido poderosamente en la manera de pensar.

3.4.2. Se ve, pues, que fuera del alma el tiempo es sólo el movimiento. $\mathbf{Y}$ se llama tiempo al movimiento que sirve para medir otros movimientos, para lo que se requiere que el movimiento medida reúna condiciones como regularidad, uniformidad, continuidad. Alberto de Sajonia, conocido como Albertus parvus por contraste con Albertus magnus, ${ }^{38}$ precisa las condiciones que deben ser satisfechas para que un movimiento sirva de medida de otros movimientos: debe ser en lo posible regular, del mismo género de lo medido (unigenium), conocido común, aceptado por todos y con un mínimo apreciable al sentido y manejable como instrumento. De esa suerte cualquier movimiento conocido por nosotros puede

36 El texto de Juan de Baconthorp (-1348), reproducido por Anneliese Maier, op. cit., pp. 66-67, es el siguiente: iste articulus non potest intelligi contra aliquos ponentes qui tenerent quod tempus nihil est quantum ad suum fundamentum, quod est motus, quia numquam fuit aliquis ita rudis errans de modernis philosophantibus, qui negavit motum esse ens extra intellectum. Ergo intelligitur quod sit error, quod (tempus) nihil sit in re sed solum in apprehensione, secundum quod est numerus motus. Este artículo no puede entenderse contra los que suponen que el tiempo no es nada en cuanto a su fundamento sino el movimiento, porque nunca hubo alguien entre los filósofos modernos que errara tan toscamente al negar que el movimiento fuera algo real fuera de la mente. En consecuencia se entiende que el error sea por afirmar que el tiempo no sea nada en la realidad (in re) sino sólo en la aprehensión, según que es el número del movimiento.»

37 Lo que parece condenar el Decreto es la duda sobre el carácter real de la duración de las criaturas. Si el tiempo es subjetivo, esta duración es en verdad una ficción del alma provocada por la percepción del movimiento. Roland Hissete (op. cit., p. 154) escribe: Cette insistence sur l'apprehension a sans doute éville l'inquietude d'un censeur: il a cru que certains maitres contestaient le caractère réele de la durée des créatures.

s8 Se le conoce también por Alberto de Helmstedt, Alberto de Ricmestorp o simplemente Albertutius (Albertito). Enseñó en Paris desde 1351. Fue rector de la Universidad de Paris en 1353. Primer rector de la Universidad de Viena, fundada en 1365. Obispo de Helmstedt desde 1366. Murió en 1390. 
ser tiempo: quilibet motus a nobis cognoscibilis potest esse tempus, si por él podemos medir otros movimientos. ${ }^{39}$

4. Como es sabido, Copérnico invierte el sistema aristotélico-escolástico tradicional y establece las respectivas equivalencias a fin de explicar las apariencias. No es el cielo el que gira sino la tierra sobre su eje y alrededor del sol, al igual que los demás planetas. Pero si el cielo no se mueve, entonces no puede ser la medida del tiempo. La tierra se convierte por necesidad del sistema en el órgano del tiempo. Por eso decía Galileo que Copérnico hizo de la tierra no sólo una estrella entre las estrellas sino que la convirtió en il primo mobile.

Nosotros pensamos que ese cambio no hubiera sido posible si antes no se hubiese establecido que el cielo no era fundamento real del tiempo y que el reloj cósmico podía ser cualquier movimiento que reuniera las condiciones de uniformidad y continuidad. Si recordamos que la definición del tiempo de Aristóteles exige la realización de un movimiento que sea la medida real y absoluta del tiempo, el que no podía ser otro que el primum mobile, comprenderemos entonces que en la inversión del sistema el movimiento de la tierra tenía que jugar el rol del primer cielo en la formulación aristotélica. Petrus Ramus a comienzos del siglo xvi decía que Copérnico "quitó el movimiento al cielo (caelo detraxit omnem motum) y que con el solo movimiento de la tierra medía mucho más exactamente (longe exactius) que los astrónomos tradicionales". ${ }^{40}$

Copérnico tuvo entonces que demostrar en virtud de qué principios la tierra se mueve, puesto que la prueba empírica no era posible en aquella época. Todo el libro primero de De revolutionibus orbium está dedicado a probar que la tierra se mueve con naturalidad, uniformidad y exactitud, pero porque se supone que es una esfera perfecta.

Pero antes de que se pudiera pensar que la tierra era una esfera perfecta debió ser posible la consideración de que era una estrella como las demás en el firmamento. Para los griegos -y esto es lo que hizo posible la concepción aristotélica del tiempo- el cielo es eterno y su movimiento uniforme porque está constituido de una materia diferente a la de los cuerpos sublunares: el éter. La palabra "éter" debe haber tenido entre los griegos una significación que hoy nos resulta extraña.

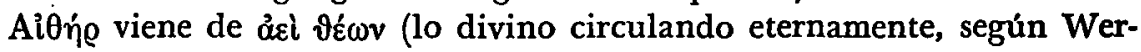
ner Kranz). ${ }^{41}$ Aristóteles, sin embargo, no pensó que la esfericidad del cielo era condición suficiente para el movimiento del mismo. Sin el motor

39 Citado por A. Maier, op. cit., p. 11747.

40 Scholae Physicae, Parfs, 1565, IV, 11-14 (reimpresión de la ed. de 1606: Frankfurt, 1967, pp. 119-123).

41 Kosmos, Bonn, 1958, p. 89. 
inmóvil ese movimiento no es posible, pues el movimiento circular no es natural para el Estagirita.

Para el pensador cristiano esto es inadmisible, puesto que la realidad está constituida por Dios y la creación. Esto es, nada de lo que no sea Dios puede ser divino. Si bien se admitió durante la Escolástica que el cielo y los astros estaban constituidos de una naturaleza superior, ello no se debía a que su materia fuera diferente de la de los cuerpos sublunares, sino a su composición. La perennidad de la constitución de los astros, su sempiternidad, se explicaba porque la forma de ellos actualiza totalmente la potencialidad de la materia de que están hechos, de modo que todo el apetito de ésta se halla saciado en su forma. Satiatur enim ab illa forma totus illius materiae appetitus, escribe Zabarella. ${ }^{42}$ Es indudable que esto constituye un paso decisivo hacia la homogeneización del universo; se abre por decir así la posibilidad de una física del universo.43

Durante la Escolástica se pensaba que los astros se movian uniformemente en esferas, pero no habla unidad de parecer sobre si se movian por sí mismos en virtud de una tendencia natural, o si -como era la opinión mayoritaria - eran movidos por Dios, los ángeles o por estar dotados de alma. Interesante es registrar aquí la cuestión planteada simultáneamente en 1271 a Santo Tomás de Aquino y a Roberto Kildwardby por el Maestro General de la Orden de los Predicadores, Jean de Verceil: " $¿ E s t a ́$ probado que los ángeles son los motores de los cuerpos celestes?" era una de las cuestiones, entre otras 43 , puestas en consulta por Verceil. Santo Tomás respondió que es imposible que los astros se muevan por su propia naturaleza y que, a menos que no sean movidos por Dios inmediatamente, ellos son movidos por los ángeles o por sus

42 De natura caeli, en Opera, Colonia, 1597, p. 270. Cit. por Blumenberg, Die Genesis der kopernikanischen Welt, Frankfurt, 1975, p. 545. Zabarella, quien fue un aristotélico del Renacimiento (1533-1589), reproduce sin embargo una idea corriente en la Escolástica sobre la constitución de los cuerpos celestes. Roger Bacon escribe a este respecto que "causa incorruptionis in angelo et caelo, ut omnes concedunt, est quia forma complet totam potentiam materiae in eis et appetitus eius finit". Opus tertium. En Opera quaedam hactentus inedita, Londres, 1859, p. 123. "La causa de la incorruptibilidad del ángel y el cielo, cosa que todos admiten, es porque la forma completa (satisface) toda la potencia de la materia en ellos y el apetito de ella (la materia) termina."

43 La teoría aristotélica del cielo es en verdad ajena a la física. Las leyes del movimiento no son aplicables al movimiento estelar. Los astros son para Aristóteles y los griegos - como ya hemos visto_- divinos. La desdivinización de los astros por efecto de la creencia cristiana de un Dios absolutamente trascendente a la creación, favorece la homogeneización del universo y la universalización de las leyes de la física. “... la discrimination entre (le Creatur) ct tout le crée dechoit les astres de leur divinité, même s'ils demeurent d'une essence supérieure aux corps infralunaires, générables et corruptibles; la figure de ce monde n'est plus une structure necessaire, mais une donnée de fait essentiellement contingente dans sa dépendance d l'égard de la puissance créatrice". Vignaux, De Saint Anselme d Luther, París, 1976, p. 72. 
propias almas. Roberto de Kilwardby opinó en cambio que Dios ha podido hacer los astros de tal forma que ellos se muevan naturalmente en círculo, así como los graves tienden a moverse en línea recta hacia el centro del universo y los ligeros hacia la periferia del mundo sublunar.44 Esta confrontación prueba que ya entonces se consideraba como posible que los cuerpos celestes se muevan eternamente en círculo en virtud de su propia naturaleza. Roger Bacon en un escrito de entre 1265 y 1269 dice que "así como los elementos buscan moverse fuera del medio, tales los livianos, y otros hacia el medio, tales los graves, así el cielo se mueve en virtud de su naturaleza alrededor del medio" (sic caelum fertur circa medium a natura sua)..45 Bacon distingue empero entre el movimiento natural alrededor del centro del mundo y los movimientos excéntricos y los epiciclos, los cuales no son naturales sino voluntarios, quia non sunt circa centrum naturale mundi. ${ }^{48}$ Pero una cosa es que el movimiento circular alrededor de un centro sea natural en algunos cuerpos y otra que el movimiento sea regular y uniforme en virtud de la forma, cualquiera que sea el cuerpo. La misma distinción que hace Roger Bacon entre el movimiento natural alrededor del cielo y la anormalidad de los movimientos excéntricos y los epiciclos, que, no obstante que son movimientos circulares perfectos no son empero naturales, nos hace pensar que los movimientos naturales son en virtud de un orden y no en virtud de las formas.

Sin embargo, ya en el siglo xir se especula sobre propiedades cinemáticas de las formas. En 1235 Villard de Honnecourt publica su Libro de los constructores donde relata los esfuerzos de los arquitectos por construir la rueda perfecta que se mueva "por ella sola". ${ }^{47}$ Se busca el perpetuum mobile en la forma circular o en las esferas perfectas. Buridano impresionado por el movimiento de los molinos de piedra que sólo se detienen por la fricción, sugiere que las inteligencias angélicas podrían no ser necesarias para mover las esferas celestes, las que quizás rotan por un impetus inicial. ${ }^{48}$ Es entonces la forma esférica y circular condición para el movimiento perfecto. Nicolás de Cusa dice, en efecto, que la

4 M.-D. Chenu, Aux origines de la "science moderne". En Reure de sciences philosophiques et theologiques. París, 1940, vol. 29, pp. 206-216.

\$5 Communium naturalium, OHI, II, Oxford, 1910 (?), p. 116.

10 Loc cit., "porque no son alrededor del centro natural del mundo".

${ }_{4} 7$ "Maint jor se sunt maistre desputé de faire torner une ruée li seule ..." Villard de Honnecourt, Bauhüttenbuch, ed. de H. R. Hahnloser, Wien, 1935.

48 "Jean Buridan ... impressed by the fact that a rotary grindstone, once set in motion, is stopped only by friction (resistentia), suggests that the angelic intelligences may not be needed to move the celestial spheres, which perhaps rotate by an initial impetus." Lynn White Jr., Medieval Technology and Social Change, Oxford, 1962, p. 1745 . 
forma esférica es aptissima ad perfectionem motus, a la que si se pone en movimiento, éste no cesará jamás (numquam cessabit). ${ }^{40}$

Los casos citados, concretamente los de Villard de Honnecourt, Buridano y Cusa, hacen pensar que ya en ellos funciona una idea de movimiento diferente a la tradicional. Según la tradición aristotélico-escolástica no hay, ni es posible, un movimiento natural eterno. Pues todo movimiento natural lo es por ser una tendencia al reposo. "Natura numquam inclinat ad motum propter movere, sed propter aliquid determinatum quod ex motu consequitur" dice Santo Tomás de Aquino. ${ }^{50} \mathrm{El}$ movimiento del primer cielo es eterno pero por efecto de la acción constante del motor inmóvil, que, como hemos visto, Aristóteles identifica con Dios. En cambio los autores citados conciben un movimiento incesante sólo en virtud de la forma. Forma y movimiento adquieren una cierta funcionalidad independientemente de la materia de los cuerpos. No es necesario ya -como acontecía en la tradición aristotélico-escolástica- suponer una materia especial, la quinta essentia, apta para el movimiento eterno.

Pero aquí es pertinente hacer una distinción entre postular que la forma esférica perfecta es apta para el movimiento regular y continuo, y afirmar que la forma esférica es causa del movimiento. La idea de que la forma es causa de movimiento puede hallarse en el Timeo de Platón y antes en los atomistas. Según éstos, la forma del átomo determina su movimiento. Los átomos de fuego y los del alma tienen un movimien. to autónomo debido a su forma.

Copérnico conoció sin duda las ideas de Platón y los atomistas concernientes a la esfericidad y el movimiento, pero no podfa aceptarlas por dos razones. La primera, porque introduce dentro del sistema la necesidad y de esa suerte la naturaleza escapa del reino de lo contingente, que caracteriza a todo lo creado por oposición al Creador. Ricardo de Mediavilla ha expresado que la esfericidad no es causa necesaria de movimiento, pues entonces Dios no podría paralizar el cielo sin destruirlo. Resultaría así una situación contradictoria: una esfera perfecta, como el cielo, sin movimiento. ${ }^{51}$ La segunda, porque ello llevaría a una dificultad seria dentro del sistema heliocéntrico, que postula que el cielo de las estrellas fijas y el sol son inmóviles, con un aparente movimiento causado por el movimiento real de la tierra. Sin embargo, el cielo de las estrellas fijas y el sol son esferas perfectas. Por eso Copérnico concluye

48 De ludo globi, I.

50 De potentia, V, 5. \&a naturaleza nunca se inclina hacia el movimiento por el movimiento, sino por algo determinado que se consigue mediante el movimiento.»

51 Ricardo de Mediavilla, II Sent. I. 14, q. 6. Citado por A. Maier, Zwei Grundprobleme der scholastischen Naturphilosophie, Roma, 1951, p. 190. 
que la esfericidad es una aptitud para el movimiento perfecto (forma rotunditatis ad perfectionem motus est aptissima) y que una vez puesta en movimiento no cesará de moverse, en lo que sigue al Cusano. Aunque a decir verdad, la influencia de Nicolás de Cusa sobre Copérnico termina allí. Nicolás de Cusa señala que las figuras perfectas son invisibles, esto es, incorpóreas, en consecuencia la perfección de una forma trasciende la objetividad física (Nam rotunditas, quac rotundior esse non posset, nequam est visibilis). ${ }^{52}$ Para Copérnico, por el contrario, el fundamento de todo su sistema heliocéntrico está en que la tierra es una esfera perfecta y es en virtud de esa redondez que se mueve con regularidad y continuidad, haciendo las veces —en la inversión- del motus primus.

Que la tierra es redonda es algo que se aceptaba desde antiguo y en esto no hubo novedad. Aristóteles señala incluso una prueba objetiva de esa redondez en el arco que se forma en la luna creciente y menguante. Además, el sistema geocéntrico implica que los elementos pesados de la tierra tienden hacia el centro del mundo. La presión que ejercen estos elementos desde todos los radios al centro del universo conforma al final una esfera. Lo interesante es observar que esta prueba de la redondez de la tierra que se deriva del modelo geocéntrico del universo, se funda en una idea de movimiento finalista, esto es, los cuerpos se mueven naturalmente buscando el lugar que les corresponde según su naturaleza: los cuerpos pesados (gravia) buscan por tendencia natural el centro, que coincide con el centro del universo. De allí que en la concepción geocéntrica la tierra resulte inmóvil. ${ }^{22 a}$ Copérnico no parte de ninguna observación para afirmar que la tierra es una esfera perfecta y que por ello se mueve con regularidad, a no ser la de señalar el eclipse total de Iuna como imagen de esa redondez. ${ }^{53}$ Para contrastar métodos recordemos que Tolomeo, fiel a una regla metodológica observacional, parte del fenómeno y sólo se limita a afirmar lo que es compatible con él. Tolomeo concluye de la observación la órbita circular de las estrellas observadas. La forma esférica del cielo no es un resultado de la observación, pues escapa a ella, y sólo se concluye a partir de la circularidad y paralelidad de los movimientos de las estrellas. Copérnico al contrario procede especulativa y deductivamente a partir de la idea de que el

52 Nicolás de Cusa, loc. cit.

52a Si bien la tierra es redonda para Aristóteles, no es empero una esfera perfecta. Las figuras o formas de los cuerpos sublunares -en contraste con las estelares - no pueden ser perfectas. De allí que la física aristotélica no pueda expresarse en cantidades sino más bien en calidades: es una física cualitativa. La física moderna es fisica matemática.

53 Op. cit., I, 3: . . qualem (sic. figuram) umbram ipsius estendit: absoluti enim circuli amfractibus Lunam deficientem afficit. Citado por Blumenberg, Die genesis kopernikanischen Welt. Frankfurt, 1975, p. 57858 \&... muestra una tal (figura) como la sombra de sí misma; la tierra eclipsa la luna según la forma de un círculo perfecto.s 
mundo tiene una forma esférica porque ésta es la forma perfecta de un todo integrado que garantiza la mayor cohesión y permanencia. Además, agrega Copérnico, esta forma ideal de la esfericidad se muestra como el fin al que tienden las cosas, lo que ya se ve de manera realizada en los astros (el sol y la luna son redondos), pero también en la forma esférica en que buscan estabilizarse por ejemplo las gotas de agua; quod in aquae guttis caeterisque liquidis corporibus apparet, dun per se terminari cupiunt. ${ }^{54}$

La teoría heliocéntrica no fue desconocida en la Antigüedad. Aristarco en el siglo III a. C. la enunció, aunque se desconoce en qué forma. De la teoria heliocéntrica de Aristarco se sabe sólo por los argumentos esgrimidos para refutarla. Tolomeo da dos argumentos en contra: ¿por qué las nubes giran con la tierra? y ıpor qué no aparece ningún paralaje no obstante que la tierra al girar alrededor del sol describiría un largo trayecto que harfa cambiar la posición de ésta con respecto a las estrellas fijas? Buridano y Oresme en el siglo xIv retoman estas argumentaciones y en cierta manera las revisan a fondo para desvirtuarlas en parte. Si la tierra gira sobre su eje tendría que suceder alguna de las siguientes anomalías alternativas: a) La tierra giraría de oeste a este y las cosas que están en el aire y el aire mismo quedarían desplazados hacia el oeste; b) el aire giraría con la tierra como parte de ésta pero las cosas que están en el aire, las nubes por ejemplo, se quedarían retrasadas en el oeste; c) tanto el aire como las cosas en él girarian conjuntamente con la tierra, entonces no se percibiría ningún cambio en la posición de las cosas en el aire. Ninguna de estas cosas se ha observado. En consecuen. cia, la tierra no se mueve. Buridano incluso aporta un argumento más, originado en su teoria del impetus. Un proyectil lanzado verticalmente debería caer en un lugar al oeste del sitio de donde fue lanzado, porque el impulso asimilado por el proyectil lo mantendría en la dirección dada, aunque el aire girase con la tierra. Esto sin embargo no se observa.

Fuera de las dificultades anotadas, que son de orden físico, tanto Buridano como Nicolás de Oresme —con más énfasis este último- opinaron que no hay modo de saber astronómicamente cuál sistema es el correcto, si el geocéntrico o el heliocéntrico. Oresme señala incluso las ventajas de este último que pueden resumirse en tres: a) el sistema heliocéntrico resuelve el problema de los movimientos aparentemente contrarios en el cielo, entre los planetas y las estrellas fijas; b) la velocidad del movimiento de la tierra sería muchísimo menor que la que se supone tendría el cielo de las estrellas fijas en el sistema geocéntrico; c) por úl-

54 Copérnico, De revolutionibus orbium caelestium, I, I: alo que se observa en las gotas de agua $y$ en otros cuerpos liquidos, que buscan por si limitarse (en formas esféricas).: 
timo, corresponde más a la dignidad de los cuerpos celestes el reposo que a la tierra, cuyo rango es inferior. No obstante estas ventajas, que expresan la simplicidad del sistema heliocéntrico, Oresme lo desecha "porque contradice no sólo a algunos artículos de la fe, sino también a la razón natural y al entendimiento común". ${ }^{65}$

Como se ve, el terreno ya estaba abonado para Copérnico. No es improbable que éste haya tenido acceso a las obras de Buridano y Oresme, que eran conocidas en Europa Oriental y que en la Universidad de Cracovia eran estudiadas a fines del siglo xv cuando Copérnico era estudiante de ésta. De toda suerte, es notorio que los argumentos en favor del sistema heliocéntrico de Buridano y Oresme fueran utilizados por Copérnico.

La concepción de que la tierra es una esfera perfecta y de que, en consecuencia, su movimiento es natural resuelve fácilmente y con elegancia el problema de los supuestos trastornos causados por un movimiento de gran velocidad, como sería el de la rotación y traslación de la tierra. No hay razón para suponer que un movimiento natural sea causa de anomalías en un todo integrado y cohesionado, del que forman parte las nubes, el aire y las cosas sobre la superficie de la tierra, quae vero a natura fiunt recte se habent et conservantur in optima sua compositione. ${ }^{36} \mathrm{La}$ ausencia de paralaje, que era una de las dificultades que hacían inaceptable la teoría heliocéntrica, según hemos visto, la supera Copérnico aduciendo que ese paralaje es imperceptible por la gran distancia a que se halla el cielo de las estrellas fijas con respecto a la tierra. El paralaje fue encontrado por Bessel recién en el siglo xIx.

El sistema copernicano se afirma en supuestos, cuyo origen es antiguo y que al usarse para probar un sistema opuesto al tradicional lo hacen justamente admisible, en un medio hostil al cambio. Hemos visto estos supuestos: la esfericidad como principio de movimiento, el movimiento natural como opuesto al movimiento violento, la concepción de que el reposo es más digno que el movimiento, etcétera; los mismos que se utilizaron para fundamentar el sistema geocéntrico y que Copérnico usa -basándose en antecedentes más cercanos a él, según hemos visto- justamente para su nueva concepción. La consolidación definitiva del sistema copernicano en el siglo xvi se va a basar empero en la destrucción y el remplazo de esos supuestos que la camuflaron en un primer momento, por sus opuestos, esto es, que la tierra no se mueve por ser una esfera perfecta sino justamente al revés: su deformación prueba antes

55 Edward Grant, Das physikalische Weltbild des Mittelalters. Trad. del inglés, Zürich, 1980 , p. 1221.

56 Copérnico, op. cit., I, 8. «pero lo que sucede según la naturaleza se tiene adecuadamente y se mantiene en su mejor composición.» 
bien que se mueve; que los planetas no giran alrededor del sol en circulos perfectos sino en elipses; que el movimiento de rotación no es natural sino un movimiento complejo. En suma, la explicación del movimiento no es en virtud de las formas sino de la acción de fuerzas. En lugar de la explicación puramente cinemática de Copérnico, Newton nos va a hablar de una dinámica.

5. Gilbert (1540-1603) descubre que el comportamiento de la aguja magnética es anormal conforme se la acerca al polo norte, lo que no se explica sino por la suposición de que el norte magnético no coincide con el norte geográfico, lo que a su vez resultaría de una deformación de la tierra. La comprobación de esa deformación la hará recién Maupertius en 1736 en un viaje de estudios al Polo Norte: la tierra es achatada en los polos. Kepler (1572-1631), a partir de los datos astronómicos proporcionados por Tycho Brahe (1546-1601), concluye que la tierra y los planetas no describen circulos perfectos al moverse alrededor del sol sino elipses. Cassini en 1666 observó que el planeta Júpiter muestra un achatamiento en los polos del eje sobre el cual gira. Estos hechos y otros observados por Newton respecto de la luna lo llevaron a pensar que el movimiento no se debe a la forma esférica perfecta de los cuerpos ni a la circularidad, sino al contrario: las deformaciones observadas son justamente pruebas del movimiento. Si los cuerpos fueran esferas perfectas se probaría con ello lo contrario de lo que Copérnico suponía: que no se mueven. Los movimientos de rotación y de traslación son complejos, se dan como resultado de una composición de fuerzas. El abultamiento de los esferoides por el ecuador muestra una fuerza centrifuga que no es otra que la tendencia inercial del cuerpo a continuar en un movimiento rectilíneo y uniforme. De modo que el movimiento de rotación y el circular no son en modo alguno movimientos naturales.

El movimiento inercial supone que el móvil recorre espacios iguales en tiempos iguales, se trata de un movimiento uniforme absoluto. Pero esta misma uniformidad de movimiento no se concebiría sin un tiempo absoluto que discurre uniformemente independiente de todo movimiento y que no sólo define, sino que permite concebir el movimiento inercial: seu currant res, seu stent, seu dormiamus, sive vigilemus, aequo tenore tempus labitur, escribe I. Barrow, el maestro de Newton en un libro editado por éste en $1669 .{ }^{57}$ Pero el movimiento inercial por ser absolutamente uniforme y rectilíneo no sería un movimiento absoluto

57 Antes que Barrow, Gassendi expone la misma idea del tiempo y en similar forma: "tempus, seu sit aliquid quod ipso duret, seu non sit; et seu quiescat, seu moveatur; et seu moveatur ocyus, seu segnitus; oedem tenere semper labitur". Y ya en 1644 en sus objeciones a Descartes escribe: "sive res sint, sive non sint, sive moveantur, sive quiescant, eodem semper tenore fluit tempus". "Sea que exista algo que dure por st - que no exista, sea que repose o que se mueva, sea que se mueva rápida o lenta- 
sino relativo, pues varios movimientos inerciales paralelos serian a la postre relativos, según el sistema de referencia. Sin embargo, la presencia de la fuerza centrífuga (inercial) en el movimiento compuesto prueba la realidad del movimiento en un espacio absoluto, según Newton.57a $\mathrm{De}$ esa suerte, el "movimiento natural", que sería el puramente inercial, es un tope ideal explicativo del movimiento real, que no es natural. ${ }^{58} \mathrm{De}$ esta manera no hay movimiento regular absoluto. "Los dias naturales que se tienen por el vulgo como iguales son en verdad desiguales - dice Newton- los astrónomos han corregido esta desigualdad. Es posible, sin embargo, que no haya en absoluto movimiento uniforme por el que el tiempo sea medido exactamente." 59 "Todos los movimientos pueden ser acelerados o retardados, pero el flujo del tiempo absoluto no está ligado a ningún cambio. La duración o la perseverancia de la existencia de las cosas permanece la misma aunque los movimientos sean rápidos o lentos o no haya movimiento en absoluto. En consecuencia esta duración absoluta debe distinguirse de las que son sólo medidas sensibles de ésta." tiempo no es ya la medida del movimiento ni está en algún modo vinculado con éste. Hemos visto que a lo largo de toda la tradición cristianooccidental se vinculó de modo necesario al tiempo con el movimiento. Agustín al rechazar la idea de que el cielo fuese sujeto del tiempo señalaba que era suficiente con que la "rueda del alfarero" siguiera rotando para que hubiera tiempo, con lo que quería significar que en tanto hubiera cambio habría tiempo. Ahora bien, la estructura de la criatura es justamente temporal porque cambia permanentemente. Todo lo creado es contingente. Es cierto que para la Escolástica hay cosas creadas que no cambian y que por eso no están en el tiempo ni son temporales: los ángeles. ${ }^{61}$ Geraldo de Odonis en el siglo xIv sugiere

mente, el tiempo discurrirá siempre ininterrumpidamente. $Y$ ya en 1644 en sus objeciones a Descartes escribe: "Sea que las cosas existan o no, que se muevan o estén en reposo, el tiempo fluye siempre e ininterrumpidamente de la misma manera." Citado por B. Rochot, "Sur les notions de temps et d'espace chez quelques auteurs du xvir siècle, notamment Gassendi et Barrow"; en Revue d'histoire des sciences et de leurs applications, 9, 1956/1957.

57a El movimiento en el vacio no es infinito, como sin embargo lo afirmaba Aristóteles argumentando con ello su imposibilidad, sino que tiene una velocidad que depende de la fuerza inercial. Ésta es la novedad de la física del siglo xvir. De manera que la velocidad de los diferentes movimientos inerciales no tiene que ser la misma. Esto lleva a la conclusión de que el movimiento inercial es relativo.

58 "La presencia de las fuerzas centrifugas confirmó no sólo la realidad del movimiento frente al espacio absoluto, sino también el fin de la 'naturalidad', esto es, de la inercialidad de la rotación." Blumenberg, Die Genesis der kopernikanischen Welt, p. 598. Para Newton el movimiento real es justamente el que no es natural.

59 Principia, II, 8.

60 Principia (ed., de 1687), Scholium a Definitiones. Citado por Royré, Newtonian studies, Londres, 1965, p. 104.

61 A. Maier Metaphysische Hintergründe ..., p. 9612: "Das aevum (aeternitas crea- 
-aunque no lo sostiene abiertamente por no contravenir al peso de la tradición- que ya en la creación del segundo ángel hay una secuencia de un antes y un después que es evidentemente temporal, con lo que el tiempo alcanza también a las cosas que duran pero no cambian, esto es a toda la creación. ${ }^{62}$ Para Newton, empero, el tiempo absoluto no está vinculado con la existencia: podrían las cosas no existir y el tiempo seguirá fluyendo uniformemente (aequabiliter fluit). ${ }^{62 a}$ Es sabido que Newton afirmó que el espacio absoluto es la manera como Dios siente el mundo: el espacio es el "sensorium Dei". No se sabe sin embargo que haya dicho algo semejante con respecto al tiempo absoluto. Alexander Koyré nos dice que este tiempo absoluto es la duración de Dios, para Newton. (Newton does not tell us, but we know the answer: the dura-

ta oder aeternitas participata) ist die mensura durationis, das Mass für das Sein, der Intelligenzen oder Engel, die zwar geschaffen, aber unvergänglich sind und darum ausserhalb der Zeit liegen. Duratio ist hier (und überhaupt in allen scholastischen Diskussionen über Zeit, aevum, Augenblick und was damit zusammenhängt) immer ohne zeitlichen Beiklang verstanden ..." "La duración sin límites (la eternidad creada o la eternidad participada) es la medida de la duración, la medida del ser de las inteligencias o ángeles, que siendo creados son en verdad imperecederos y están por eso fuera del tiempo. La duración es aqui (y en general en todas las discusiones escolásticas sobre el tiempo, el aevum, el momento y todo lo que a ello concierne) entendida sin connotación temporal ..."

62 Geraldo Odonis habría afirmado - según Juan Canonicus: Phys. IV, q.5 a.3 - dos cosas concernientes al tiempo: "prima est quod tempus habuit esse ante mundi initium et inceptionem cuiuslibet creaturae, sic quod fuit ab aeterno ... Secunda conclusio quam ponit est ista, quod tempus non est passionec sequela motus". Aparentemente hay pues un tiempo que existe independientemente de toda existencia y no sólo del movimiento. Pero según la argumentación del mismo Geraldo para llegar a la primera conclusión, reproducida por Juan Canonicus en el lugar citado podría pensarse otra cosa. Según Geraldo, antes de la creación hay la posibilidad de crear los ángeles. Ahora bien, se crea un ángel sin que ninguna otra cosa se haya producido. Se supone luego que se produce un segundo ángel que no se había producido antes. Este ángel fue producido con el primero o después. La primera alternativa es imposible. Luego este ángel es posterior y el otro anterior. La relación anterior-posterior es temporal (prius et posterius sunt ipsum tempus). El tiempo, pues, está vinculado con la creación o con la posibilidad de la creación, pero no con el movimiento, del que es independiente, según la segunda conclusión. De esa manera, no parece que para Geraldo el tiempo sea independiente de toda existencia. Se ha afirmado que Geraldo Odonis habría formulado la idea newtoniana de tiempo tres siglos antes. Pero el tiempo newtoniano es diferente, fluye independientemente de si existen o no existen las cosas; es un tiempo matemático cuya característica es una absoluta uniformidad; es un presupuesto del concepto de inercia (v. nota 62a).

62a ... time is not measure of motion, as the school defined it, nor is the duration of things, their amount of being, as Descartes defined it. Time has its own nature, independent of everything "external", that is, independent of the existence or non existence of the world. If there were no world, there would still be time, and duration. Koyré, Newtonian Studies, Londres, 1965, p. 103. ... el tiempo no es la medida del movimiento, como lo definió la Escolástica, ni es la duración de las cosas, como lo definió Descartes. El tiempo tiene su propia naturaleza independiente de cualquier cosa "externa", esto es, independiente de la existencia o no existencia del mundo. Si no hubiera mundo, habria aún tiempo y duración. 
tion of God. ${ }^{63} \mathrm{El}$ tiempo y el espacio no pertenecen a la contingencia del mundo, pero sirven para explicar cientificamente, según Newton, lo que acontece en el mundo. "La revolución copernicana - dice Hans Blumenberg - se abrió paso con la destrucción del concepto antiguo de realidad con su correlación de fenómenos automanifestantes y un contemplador en reposo. En cierto modo el concepto newtoniano de tiempo absoluto vuelve a caer detrás de esa posibilidad dada, pues el tiempo absoluto es a la vez un puro tiempo contemplativo. Su protagonista es la inteligencia laplaciana del mundo." ${ }^{4}$

Julio 1985

63 Op. cit., p. 104.

64 Hans Blumenberg, Die Genesis der kopernikanischen Welt, p. 515: "Die kopernikanische Revolution bewegte sich in einem Spielraum, der durch die Destruktion des antiken Wirklichkeitsbegriffs mit seiner Korrelation von sich zeigenden Phänomen und ruhendem Zuschauer eröffnet worden war. In gewisser Hinsicht ist Newtons Begriff der absoluten Zeit hinter der derart gegebenen Möglichkeit zurückgefallen, den die absolute Zeit ist zugleich eine reine Zuschauerzeit. Ihr Protagonist ist die Laplacesche Weltintelligenz." Cf. lo dicho en 2.4 del presente trabajo. 